\title{
LA COLABORACIÓN DE LAS PARTES Y DE TERCEROS EN LA PRODUCCIÓN DE LA PRUEBA, CON ÉNFASIS EN LA PRUEBA PERICIAL
}

\author{
PARTIES AND THIRD PARTIES COOPERATION IN EVIDENCE \\ PRODUCTION. WITH PARTICULAR FOCUS IN EXPERT'S \\ REPORTS EVIDENCE
}

IGNACIO M. SOBA BRACESCO ${ }^{*}$

\section{Resumen}

La regulación de la colaboración ha merecido la atención de los sistemas legales-procesales que, poco a poco, han abandonado el paradigma clásico. Mientras que en algunos casos los litigantes se encuentran con la carga de colaborar, en otros, se les imponen verdaderos deberes de colaboración. La distinción resulta relevante, dada las distintas implicancias que podría tener la ausencia o falta de colaboración. Asimismo, se analizarán conductas específicas en las que se materializa la colaboración procesal de las partes y de terceros respecto de la prueba pericial.

\section{Palabras clave}

Colaboración procesal, carga, deber de colaboración, prueba pericial.

\begin{abstract}
Procedural cooperation has merited the attention of legal-procedural systems that have abandoned the classical paradigm. While in some cases, litigants are burdened with the burden of collaboration, in others, real duties of collaboration are imposed on them. The distinction is

1 " Profesor Adjunto contratado y Profesor Adscripto de Derecho Procesal por la Facultad de Derecho de la Universidad de la República. @IgnacioSoba - ignaciosoba@gmail.
\end{abstract}


relevant because of the different implications that the absence or lack of collaboration could have. In addition, we will analyze how the procedural cooperation of the parties and third parties is materialized with respect to the expert evidence.

\section{Keywords}

Procedural cooperation, burden, duty of cooperation, expert evidence.

"El litigante está motivado para presentar solo aquellas pruebas que le sean favorables: si un elemento de información se le antoja desfavorable para sus intereses, intentará mantenerlo fuera de los tribunales, incluso si su relevancia para la búsqueda de la verdad es indiscutible."2

\section{Introducción}

La colaboración de las partes y de terceros en el proceso es un tema polémico, posible de diversas controversias. ${ }^{3}$ Para algunos, no solo aquellos ajenos a la disciplina, sino también estudiosos del derecho procesal, puede hasta resultar extraño referir a la colaboración en el proceso, siendo que siempre ronda la idea de que, en ese ámbito de lo contencioso, del litigio o el conflicto, o de relatos y argumentos forenses contrapuestos - incluso hasta irreconciliables en el plano fáctico y normativo del caso concreto-, es

2 DAMASKA, M.: El derecho probatorio a la deriva, traducción de Picó i Junoy, J. Marcial Pons, Madrid, 2015. p. 105.

3 Por terceros, a los efectos de la colaboración procesal y probatoria, se entiende a personas no implicadas directamente con el objeto del proceso. Por ejemplo, se trata de personas que no son las partes ni terceros que intervienen voluntaria o forzosamente en el proceso, pero que cuentan con determinada información, documentación o datos de relevancia para el mismo. O sea, personas que no forman parte de la faz subjetiva del proceso y a quienes, por tanto, no alcanza la cosa juzgada. Algo similar se extrae $-a$ contrario sensu- del art. 330 de la Ley de Enjuiciamiento Civil (LEC) española 1/2000, relativo a la exhibición de documentos en poder de terceros, cuando se indica que: “...no se considerarán terceros los titulares de la relación jurídica controvertida o de las que sean causa de ella, aunque no figuren como partes en el juicio.". 
casi imposible pensar en términos o criterios de ética, moralidad, diálogo o colaboración con el otro. ${ }^{45}$

Dentro de este vasto tema, se puede encontrar uno más específico, como lo es el de colaboración en uno de los momentos más importantes de todo proceso: el de la prueba.

En el capítulo siguiente se realizarán algunas consideraciones acerca de las situaciones jurídicas procesales de carga y de deber, pues su distinción contribuye a la comprensión del objeto de estudio. Se distinguirá, además, entre consecuencias negativas por la no colaboración y la aplicación

$4 \quad$ Si se piensa en un modelo procesal desde la colaboración o cooperación, el diálogo resulta fundamental, y pasa a ser una pauta constante en la marcha del proceso, con influencia significativa en el mismo. En ese sentido: MITIDIERO, D.: Colaboraçao no processo civil. Presupuestos sociais, lógicos e éticos, tercera edición, revisada, actualizada y ampliada. Thomson Reuters, San Pablo, 2015. pp. 169 y ss., entre otras.

5 Un fenómeno semejante se presenta en el caso de la buena fe procesal, que ha ido evolucionando en la regulación procesal. Picó i Junoy -citando a Silva Melero- puntualiza, en ese sentido, que los códigos procesales decimonónicos “....no recogían el principio de probidad procesal muy probablemente porque partían de un concepto del proceso civil totalmente privado, como negocio particular dirigido sólo a la defensa de intereses personales, concepción totalmente superada en la actualidad, en la que el proceso se configura como el instrumento necesario para el ejercicio de la función jurisdiccional del Estado, en el que no pueden legitimarse actuaciones maliciosas de las partes tendentes a frustrar su correcto fin...". Por el contrario, en el siglo XX y comienzos del siglo XXI, ha destacado Picó i Junoy casos -como el de la LEC española 1/2000- en los que: “...resulta clara la voluntad del legislador de introducir normas de carácter ético en cuanto al modo de actuar de los litigantes. Una vez superara la visión bélica o agonística del proceso...". Cfr., PICÓ I JUNOY, J.: El principio de la buena fe procesal, segunda edición. Bosch Editor, España, 2013. pp. 30-31 y 35, respectivamente. El pasar del proceso como actividad privada, a ver en él una actividad en la cual el Estado y la sociedad están interesadas, y en la que, por ende, se busca la rectitud, la lealtad y la buena fe, es un punto compartido también por otros autores, por ejemplo: DEVIS ECHANDÍA, H.: Nociones generales de Derecho procesal civil. Aguilar, 1966. pp. 65-66. Con relación a la inserción del derecho procesal dentro del derecho público, a partir del rechazo de las teorías "contractualistas" o "cuasicontractualistas" que no logran explicar lo que acontece en el proceso jurisdiccional, véase, también: BARRIOS DE ÁNGELIS, D.: Teoría del Proceso. BdeF, Montevideo, 2005. pp. 15-20; COUTURE, E.J.: Fundamentos del derecho procesal civil, tercera edición (póstuma). Depalma, Buenos Aires, 1997. pp. 124-145. Damaska describe el panorama evolutivo del paradigma del proceso civil, señalando que, en pleno apogeo del liberalismo, los procesos civiles fueron considerados como una continuación de las relaciones privadas o como acuerdos desarrollados en el ámbito judicial: "Sólo en los últimos decenios han podido constatarse los signos de cambios (...) los aspectos de derecho público del proceso civil tienden a destacarse más que en el pasado.”. En épocas del laissez-faire, agrega Damaska, “...las sentencias civiles eran concebidas no tanto como pronunciamientos sobre el estado verdadero de las cosas, sino como decisiones que resolvían un problema -como un tratado de paz que acaba con las hostilidades-.". DAMASKA, El derecho probatorio, ob. cit., pp. 116-118 y 124, respectivamente. 
de sanciones que se pueden generar, también, ante la ausencia de dicha colaboración. Luego, se habrá de analizar concretamente la colaboración que corresponde se presten las partes y los terceros en la producción o diligenciamiento de la prueba pericial. ${ }^{6}$

El énfasis se ubicará en las conductas que se espera que las partes materialicen o desarrollen a la luz del estándar de colaboración que debería satisfacer todo buen litigante, así como en algunas conductas que se puede esperar o exigir que asuman los terceros.

Se tendrá la oportunidad de corroborar la existencia de diferentes diseños de sistemas de colaboración a nivel de la legislación procesal, recurriendo para ello al derecho comparado. El amplio elenco de normas que abordan -de forma específica o tangencial- dicha colaboración procesal, servirá como punto de partida para constatar aspectos en los que existen semejanzas y otros en los que predomina la diversidad en las formas de encarar y asumir la problemática, lo cual abre -en términos de Damaska- ${ }^{7}$ "un campo inmenso y sorprendente" propicio para seguir reflexionando e investigando.

\section{Distinguiendo entre carga y deber procesal: consecuencias procesales negativas o sanciones}

Se entiende por situación jurídica procesal, en un concepto que vincula diferentes categorías del proceso, a la posición de un sujeto - del procesorespecto de una norma (procesal) que lo comprende. ${ }^{8}$

6 Los términos diligenciamiento y producción se utilizarán aquí, indistintamente. En cuanto a la prueba pericial, vale aclarar que resulta posible encontrar prueba pericial para probar enunciados fácticos no típicamente científicos, sino más bien de índole técnico o, incluso, artísticos. De modo complementario a lo anterior, pruebas como el análisis o examen de ADN podrían ser consideradas como de tipo científico, y no estrictamente pericial. Si bien la prueba científica, entendida en una acepción amplia, permite designar "...los supuestos en que el conocimiento científico es usado en el proceso para aportar el conocimiento o la demostración de un hecho o-mejor dicho- la prueba de la verdad de un enunciado fáctico"TARUFFO, M.: La prueba. Marcial Pons, Madrid, 2008. pp. 277-278-, no será parte del presente estudio el analizar si la prueba científica y la prueba pericial son lo mismo o si se trata de conceptos dependientes, autónomos o análogos. Se debe advertir que se trata de una terminología utilizada en distintos ordenamientos jurídicos para referir a situaciones a veces diversas desde el punto de vista normativo o dogmático.

7 DAMASKA, M.: Las caras de la justicia y el poder del Estado. Análisis comparado del proceso legal. Editorial Jurídica de Chile, Santiago, 2000, p. 9.

8 Dicha definición parte de las ideas expuestas por Barrios De Ángelis, seguidas luego por Abal Oliú y Valentin. En Uruguay, con relación a las situaciones jurídicas y su 
Cuando pensamos en carga en materia probatoria casi que ineludiblemente asociamos el tema a la situación jurídica de carga de la prueba. Sin embargo, en el presente capítulo se reflexionará acerca de si la colaboración en la producción de la prueba es una carga o, por el contrario, un deber procesal. Dicha cuestión, más bien teórica, no se presenta como intrascendente desde el punto de vista práctico, terreno en el que se materializa -como será dicho- un conflicto de derechos.

Se puede partir de entender la carga -más que como un imperativo (término que se puede confundir con la idea de deber)- como la necesidad -establecida por las normas procesales- de que, para proteger el interés propio, el sujeto determine su conducta en cierto sentido. Se hace referencia a la necesidad, aunque previamente hay que destacar la libertad del sujeto; pues en la carga, y aunque pueda parecer un contrasentido, el sujeto no necesariamente debe cumplir con hacer o no el acto - allí se aprecia, aunque con restricciones, la esfera de libertad, de optar entre cumplir o no con la conducta, en el caso de colaborar-.

El sujeto colaborará - tendrá la necesidad de hacerlo- si no quiere perjudicar procesalmente su propio interés. ${ }^{9}$ De ese modo, la carga opera

conceptualización, sin pretender enumerar toda la extensa bibliografía en la materia, véase: ABAL OlIÚ, A.: Derecho Procesal, Tomo II, quinta edición. FCU, Montevideo, 2016. pp. 221-272; ARLAS, J. A.: "Situaciones jurídicas procesales". En: Revista Uruguaya de Derecho Procesal, 1/1978. pp. 26-35; BARRIOS DE ANGELIS, D.: Teoría del proceso, segunda edición. BdeF, Montevideo-Buenos Aires. pp. 115-137; El proceso civil. Idea, Montevideo, 1989; El proceso civil, segundo volumen, Idea, Montevideo, 1990; "Las situaciones jurídicas y la prueba". En: Revista Uruguaya de Derecho Procesal, 4/2001. pp. 403-408; "Acción, excepción y jurisdicción”. En: Revista Uruguaya de Derecho Procesal, 1/1999. pp. 21-30; "Las situaciones jurídicas". En: Revista Uruguaya de Derecho Procesal, 1/1998, FCU, Montevideo, pp. 31-38; TARIGO, E. E., Lecciones de Derecho Procesal Civil, Tomo I, octava edición. FCU, Montevideo, 2016. pp. 77-84; VALENTIN G.: Principio de congruencia y regla iura novit curia. FCU, Montevideo, 2013. pp. 17-42.

9 Incluso a nivel doctrinario o dogmático, frente a un mismo conjunto de textos normativos, la posición de los autores puede ser discrepante. A guisa de ejemplo, en el caso uruguayo, hay quienes entienden que lo que ha sido consagrado por las normas procesales civiles son cargas de colaborar (ABAL OLIÚ, A.: Derecho procesal, Tomo IV. FCU, Montevideo, 2014. pp. 101-102); mientras que otros opinan que se trata de claros supuestos de deber de colaboración (PEREIRA CAMPOS, S.: "El deber de colaboración en la práctica de las medidas probatorias". En: Revista Uruguaya de Derecho Procesal, 4/2000. pp. 511-523; "Moralidad, veracidad y colaboración en el proceso. Incidencia del pensamiento de Eduardo J. Couture en el proceso civil contemporáneo". En: Landoni Sosa, Á. y Pereira Campos, S.: Estudios de Derecho Procesal en homenaje a Eduardo J. Couture, Tomo I - La prueba en el proceso. La Ley Uruguay, Montevideo, 2017. pp. 247-291). Pereira Campos se ha detenido especialmente en la temática, señalando lo siguiente: "No se trata simplemente de la carga 
como un incentivo de conducta, un mecanismo de tipo psicológico, en el que en gran medida se sustenta la dinámica del proceso. Id est, aquello que lleva a las partes a realizar determinadas conductas de relevancia procesal.

En ese sentido, a la carga también se la ha considerado como un mecanismo típico de la matriz procesal liberal, por medio del cual la parte es la única responsable de su suerte procesal. ${ }^{10}$

No desconozco que podría parecer contradictorio pensar en la colaboración como una carga, cuando el beneficio que se podría estar reportando no es exclusivo del propio sujeto que colabora, sino que es un beneficio también para la contraparte y para el proceso en general, conforme la evolución del derecho procesal, a la que ya se ha hecho mención. ${ }^{11}{ }^{12}$

(...) sino que la colaboración exigida trasciende esa óptica individual y egoísta, para alcanzar la más general e intensa que corresponde a un deber jurídico de colaborar, con raigambre en los principios de buena fe y lealtad procesal. El modelo de litigante buscado por el legislador refiere a que cada parte brinde aquello que a su alcance esté para la mejor marcha de la litis (...) porque por sobre el interés privado y egoísta que pueda moverla, se ubican el interés público y valores sociales ínsitos en la actividad jurisdiccional.”. Ibídem. pp. 281-283.

10 Así, la carga se vincula también con el principio dispositivo -manifestación de la autonomía de la voluntad-, a través del cual se confía la actividad procesal al interés de las partes - para que las partes cooperen en la realización de la jurisdicción-; la carga constituye un estímulo para la actividad de las partes. Al poner a cargo de determinados sujetos las consecuencias de su inercia total o parcial, de sus acciones tardía o infundadas se convierte en un concepto fundamentalísimo, que ocupa un lugar de privilegio en el derecho procesal. VESCOVI, E. (Director); DE HEGEDUS, M.; KLETT, S.; LANDEIRA, R.; SIMON, L.M.; PEREIRA CAMPOS, S.: Código General del Proceso. Comentado, anotado y concordado, tomo 1. Ábaco, Montevideo, 1992. pp. 56-66; LANDONI SOSA, Á. (Dir.); GARDERES, S.; GOMES, F.; GONZÁLEZ, M.E.; VALENTÍN, G.: Código General del Proceso. Comentado, con doctrina y jurisprudencia, Vol. 1. BdeF, Montevideo, 2002. pp. 4-5. Todo esto, a su vez, se relaciona en alguna medida con el concepto de preclusión, como pérdida de "derechos" procesales por falta de iniciativa. El ordenamiento procesal, para asegurar el desarrollo o desenvolvimiento normal, establece algunos límites más o menos precisos o discrecionales para la actuación.

11 En la misma línea, Pereira Campos destaca que: “...se impone la colaboración de los sujetos del proceso en la producción de la prueba, lo cual no apunta a suministrar en realidad prueba 'en beneficio de la parte contraria o en perjuicio de uno mismo', sino, más bien, en miras a una más eficaz realización del Derecho. (...) Superando clásicos y antiguos moldes del proceso dispositivo puro, que favorecían la idea de que nadie puede ser obligado a producir prueba contra sí mismo, nuestro proceso civil optó (...) por política diferente..." (la cursiva es del original). PEREIRA, "Moralidad, veracidad y colaboración", ob. cit. p. 281.

12 Se podría también dudar acerca de la autonomía conceptual del concepto de carga procesal. VALENTIN, G.: Principio de congruencia y regla iura novit curia. FCU, Montevideo, 2013. pp. 35-36 (nota al pie $\mathrm{n}^{\circ} 60$ de dicha obra). 
Todo esto se asemejaría al interés general de la comunidad que se busca tutelar mediante la consagración de deberes. ${ }^{13}$

Cuando se hace alusión a la carga de colaborar, por tanto, se encuentra, por un lado, que hay un beneficio que se deriva de su cumplimiento para el sujeto que colabora y, por otro lado, un beneficio que favorece a todas las partes litigantes y hace al adecuado funcionamiento y desenvolvimiento ético y sin dilaciones del proceso. Se dota de legitimidad a la administración de justicia y se prestigia, en última instancia, al Estado de Derecho en la que aquella se inserta - siempre que al mismo tiempo se respete, por cierto, el debido proceso y la motivación de las decisiones, las que hacen al uso regulado del poder o la autoridad-. ${ }^{14}$

En similar sentido, Marinoni y Cruz Arenhart han señalado que: “... si el Estado debe solucionar el conflicto de intereses con la finalidad de aplicar el derecho -siendo ese, también, el objetivo último de la sociedad en la institución del Estado-jurisdicción-, la colectividad debe suministrar medios (de la forma más completa posible) para que la decisión jurisdiccional sea la más adecuada. De ahí que el deber de colaboración es inherente al monopolio de la jurisdicción. Además de eso, no hay que olvidar que ese deber se deriva del deber general de sujeción al poder del Estado (...) de forma que estaremos constreñidos a colaborar con el Estado para el 'descubrimiento de la verdad'.". ${ }^{15}$

A pesar de lo anterior, no es inútil perseverar en la distinción, ya que, si la situación en la que se ubica a la parte es la de carga, no existiría una sanción que conmine al sujeto a actuar de determinada manera como consecuencia de su incumplimiento.

13 Aspecto que diferencia al deber de la obligación, ya que, en la obligación, lo que se busca es imponer una determinada conducta, en beneficio de un interés particular ajeno, el del acreedor.

14 Indica Zagrebelsky, con relación al Estado de Derecho, que se trata ciertamente de una de las "más afortunadas" expresiones de la ciencia jurídica contemporánea, advirtiendo al mismo tiempo: "Contiene, sin embargo, una noción genérica y embrionaria, aunque no es un concepto vacío o una fórmula mágica, como se ha dicho para denunciar un cierto abuso de la misma. El Estado de derecho indica un valor (...). El valor es la eliminación de la arbitrariedad en el ámbito de la actividad estatal que afecta a los ciudadanos (...).", "El Estado de derecho es enemigo de los excesos, es decir, del uso 'no regulado' del poder.” ZAGREBELSKY, G.: El derecho dúctil. Ley, derechos, justicia, traducción de GASCÓN, M., undécima edición. Trotta, Madrid, 2016. pp. 21 y 29.

15 MARINONI, L.G. y CRUZ ARENHART, S.: La prueba. Thomson Reuters - La Ley, Santiago de Chile, 2015. p. 164. 
El no satisfacer la carga, en función de la libertad que ella conlleva, puede derivar en una desventaja para el propio sujeto, pero no en la aplicación de una sanción. No se encuentra prohibido no colaborar.

Si la normativa procesal no le impone una sanción al sujeto que no colabora en el diligenciamiento de la prueba, la situación de ese sujeto no podría ser más que la de carga procesal. En situaciones de carga procesal, se insiste, el no observar determinada conducta lo que puede traer aparejado es únicamente consecuencias procesales negativas. ${ }^{16}$

Las consecuencias procesales - por ejemplo, presunción en contra de quien no colabora-, podrían surgir directamente de una disposición específica que regulara un punto concreto de la carga de colaboración en materia probatoria o se podrían derivar de las consecuencias que se prevean para la falta de colaboración procesal en general.

$\mathrm{Si}$, por ejemplo, se estableciera que la consecuencia de la no colaboración procesal en general -para todo tipo de acto procesal- es una presunción en contra de quien no colabora, ${ }^{17}$ y por otro lado no se prevé ninguna consecuencia negativa concreta para la falta de colaboración en la producción de la prueba, la asignación extensiva de consecuencias negativas en materia de ausencia de colaboración en general sí sería posible.

En cambio, sería muy opinable que se pudiera utilizar un razonamiento similar - esto es, extender una sanción a un caso no previsto expresamente-,

16 En materia de situaciones jurídicas subjetivas, extramuros del derecho procesal, se podría incluso cuestionar la existencia del concepto de "carga", ya que se trataría de un concepto más bien vacío - sería o bien una simple permisión o, en su caso, un deber-. Porque si la consecuencia de la conducta es una sanción, estaríamos ante un deber - siendo P colaborar en la producción de la prueba, entonces "está permitido P y está prohibido NO P" - estructura de lógica normativa de un deber-; mientras que en la carga está permitido P y también NO $\mathrm{P}$ - id est, colaborar y no colaborar-.

17 Considero que una presunción contraria al interés de una parte no permite imponer forzadamente la realización de una conducta, ni sería una sanción, sino una consecuencia procesal negativa. Una posición contraria parece ser la sostenida por Marinoni y Cruz Arenhart, quienes refieren a "la sanción de presunción". MARINONI y CRUZ ARENHART, ob. cit., p. 171. Entiendo que determinar el alcance de esas presunciones, y cuándo operan, excede el objeto del presente estudio. Aunque claro, si las consecuencias que se imponen normativamente fueran muy perjudiciales o extremadamente gravosas, se podría llegar a un punto tal en el que la distinción entre carga y deber se dificultaría enormemente. Aquí agradezco a dos amigos docentes de derecho procesal, Santiago González Miragaya y Rafael Cabrera Orcoyen con quienes estuve intercambiando ideas acerca de la línea -que en ocasiones parecería ser muy delgada- que separa la carga del deber, así como sobre el grado del perjuicio derivado de la (no) conducta de la parte. También agradezco a Darío Burstin por el aporte de su visión de teoría general del derecho. 
si consideramos que estamos ante un deber de colaboración, ya que en ese supuesto se requeriría de una sanción específica.

Las sanciones -en función de reglas o principios elementales de protección de la libertad que emanan del derecho sancionador, como son la legalidad y la seguridad jurídica- no pueden ser aplicadas analógicamente ni interpretadas extensivamente. ${ }^{18}$

Por tanto, en el plano de las consecuencias, si el sujeto no actúa o no colabora - porque ello es lo que mejor se acomoda a su interés en el proceso-, nadie podrá imponerle coactiva o forzadamente la conducta o aplicarle una sanción por su incumplimiento. ${ }^{19}$ A quien se encuentre en situación jurídica de deber sí se le puede imponer forzadamente la realización de la conducta esperada. Al decir de Valentin: "Las normas imperativas y prohibitivas (también llamadas 'normas de deber' o 'prescriptivas') requieren la realización o no realización de ciertas acciones, y prevén una sanción para las conductas contrarias. Imponen a sus destinatarios ciertos deberes jurídicos (mandatos o prohibiciones), bajo amenaza de aplicar determinadas sanciones en caso de incumplimiento". ${ }^{20}$

18 En derecho penal se extraen del principio de legalidad varias consecuencias específicas, entre ellas, según explica Silva Forné, la “...reserva absoluta de la ley para la definición de las conductas constitutivas de delito y sus correspondientes penas, (...) prohibición de la analogía in malam partem y de la interpretación extensiva, (...) determinación, certeza o taxatividad de las normas penales...". El legislador -agrega el autor citado, refiriendo a la obra de Marinucci y Dolcini- tiene la obligación de describir en modo claro y preciso los delitos y las sanciones penales - principio de precisión o de tipicidad-. SILVA FORNÉ, D.: La reforma penal. FCU, Montevideo, 2012. p. 42. Estas ideas se han ido expandiendo fuera del campo del derecho penal, siendo aplicables a otros supuestos de ejercicio de la potestad sancionatoria. Por ejemplo, en el caso del derecho administrativo español, la Ley 40/2015, de 1 de octubre, de Régimen Jurídico del Sector Público, ha recogido en su art. 27.4 lo siguiente: "Las normas definidoras de infracciones y sanciones no serán susceptibles de aplicación analógica.".

19 Nuevamente, la distinción se torna en ocasiones difusa. Se podría tratar de una cuestión de gradualismo, pues las consecuencias procesales negativas de las cargas pueden significar un condicionamiento de tal magnitud para la libertad de actuar del sujeto que, en esencia, se podría decir que son sanciones. "Una sanción es cualquier situación que vista desde la perspectiva de su destinatario constituye un estado de cosas desfavorable o negativo para ese sujeto: un mal o un estado de cosas indeseable (...), aunque no un mal natural sino uno institucionalizado."; "Las funciones de la sanción no están en su propia estructura sino en su relación con los sujetos que la padecen o se benefician de ella. (...) Por eso, un mismo evento sancionatorio puede tener funciones distintas según la perspectiva desde la cual sea observado". CAFFERA, G.: Obligaciones. FCU, Montevideo, 2018. pp. 19-20, respectivamente.

20 VALENTIN, G.: Principio de congruencia y regla iura novit curia. FCU, Montevideo, 2013. p. 25. 
Una forma de detectar la existencia de un deber de colaboración es, precisamente, en el plano de las consecuencias: por la posibilidad de imponer la conducta o por la aplicación de sanciones.

Esto es posible en los procesos civiles ya que, como ilustra Damaska: "En el proceso penal, el derecho a no declarar contra sí mismo impone serias restricciones a la utilización del acusado como fuente de prueba. Sin embargo, los litigantes civiles pueden ser obligados a declarar. Esta divergente opción de política legislativa es bastante significativa ya que los acusados son, más a menudo que los litigantes del proceso civil, los únicos individuos en posesión de información crucial para la resolución correcta del caso. A diferencia del acusado, un litigante civil puede ser obligado también a presentar documentos u otras pruebas en condiciones tales que podrían considerarse 'pesquisitorias' en el proceso penal". ${ }^{21}$

Algunos ejemplos de deberes procesales en materia probatoria podrían ser cuando se coloca a un tercero en la situación jurídica de deber para que comparezca a declarar como testigo o, en temas propios de la colaboración, cuando se le impone al tercero - o eventualmente a la parte- que franquee el acceso o exhiba determinada documentación o información. ${ }^{22}$

21 DAMASKA, El derecho probatorio, ob. cit. p. 121. En contra, se puede ubicar a Montero Aroca, quien señala que: "El intento de organizar el proceso civil de modo diferente a base de ir imponiendo deberes a las partes, deberes cuyo incumplimiento se sanciona normalmente con la imposición de una multa, es algo típico de los ordenamientos jurídicos de base autoritaria...". MONTERO AROCA, J.: La prueba en el proceso civil, quinta edición. Thomson Civitas, Pamplona, 2007. p. 121. La crítica a esta posición, explicando por qué las normas procesales civiles que consagran deberes de buena fe - y en el caso, de colaboración-, no se pueden considerar, per se, de base autoritaria, sino todo lo contrario: PICÓ I JUNOY, El principio de la buena fe, ob. cit, pp. 29 y ss.

22 Más allá de otras disposiciones a las que se hace referencia en el presente trabajo, se puede indicar como ejemplo, en Brasil, lo previsto en el art. 455 in fine de su CPC, en materia de conducción de testigos que no comparecieren voluntariamente, o el art. 458 de dicho Código, sobre deber de decir la verdad y las correspondientes sanciones penales. En Chile el art. 349 de su CPC establece -tanto para las partes como para terceros- lo siguiente: "Podrá decretarse, a solicitud de parte, la exhibición de instrumentos que existan en poder de la otra parte o de un tercero, con tal que tengan relación directa con la cuestión debatida y que no revistan el carácter de secretos o confidenciales. Los gastos que la exhibición haga necesarios serán de cuenta del que la solicite, sin perjuicio de lo que se resuelva sobre pago de costas. Si se rehúsa la exhibición sin justa causa, podrá apremiarse al desobediente en la forma establecida por el artículo 274; y si es la parte misma, incurrirá además en el apercibimiento establecido por el artículo 277. Cuando la exhibición haya de hacerse por un tercero, podrá éste exigir que en su propia casa u oficina se saque testimonio de los instrumentos por un ministro de fe." - refiere allí a las consecuencias de arresto y multa que se encuentran previstas en sede de medidas prejudiciales-. Por su parte, en España, se destaca el art. 292 de la LEC 1/2000 cuando dispone que los testigos y los peritos citados tendrán el deber de comparecer en el juicio o vista y que la infracción 
En última instancia, el consagrar cargas o deberes de colaboración -cuando se trata de las partes (que es el caso que más complejidades ofrece)- es una difícil decisión de política legislativa, que deja en evidencia la existencia de un verdadero conflicto entre derechos fundamentales, ${ }^{23}$ similar al que ilustra Picó i Junoy para el caso de la buena fe: esto es, un conflicto que se origina entre el derecho de defensa - en el caso, sería el de la parte que pretende no colaborar, porque eso sería lo que más se ajusta a su estrategia procesal concreta-, y los derechos a la tutela jurisdiccional efectiva, a la defensa - de la contraparte-, a la igualdad de armas procesales

de este deber "se sancionará" por el tribunal, previa audiencia por cinco días, con multa de ciento ochenta a seiscientos euros. Vale también aclarar que, aunque la norma catalogue a una determinada situación de "deber", ello no necesariamente condiciona al interprete, ya que ha habido -y seguirá habiendo- varios casos de uso incorrecto de la terminología técnica por parte del legislador. En el caso de Uruguay se encuentran como ejemplos la situación jurídica procesal en la que se encuentra el testigo que debe comparecer ante el tribunal, debe declarar y debe decir la verdad - Código General del Proceso, arts. 156, 160, 164, Código Penal, arts. 180 a 183 -falso testimonio y falsa exposición de peritos o intérpretes- y el deber de colaboración de terceros para la realización de inspecciones, reconstrucciones y pericias, diligenciamiento de prueba por informes - Código General del Proceso, arts. 189 y 191-. En esos supuestos, si por ejemplo el testigo no colabora con la administración de justicia y no comparece a declarar puede ser conducido por la fuerza pública hasta la Sede, a efectos que se le tome declaración.

23 Si bien siempre debe orientarse la interpretación de la norma procesal en clave constitucional, no se puede descartar que dicho conflicto derive en eventuales planteos de inconstitucionalidad - por ejemplo, argumentando que la consagración del deber de colaboración vulnera el derecho de defensa-. Es que, como ha ilustrado Picó i Junoy: "En la vida de cualquier proceso suele ser frecuente que se produzcan conflictos entre diversas garantías constitucionales del proceso (...). El ordenamiento jurídico ofrece diversas vías de solución a dichos conflictos: en algunos casos, es el propio texto constitucional que nos da la respuesta (...). En otras ocasiones es la ley la que ofrece la solución (...). Y finalmente, otras veces corresponde directamente al órgano jurisdiccional resolver el concreto conflicto...". PICÓ I JUNOY, J.: "Conflicto entre garantías constitucionales del proceso. La tensión de los derechos al recurso y a la ejecución en el caso de la ejecución provisional de las sentencias de primera instancia". En: PICÓ I JUNOY, J.: Principios y garantías procesales. Liber Amicorum en homenaje a la Profesora Ma. Victoria Berzosa Francos. Bosch Editor, España, 2013. pp. 41-42. Precisamente, los conflictos podrán ser resueltos jurisprudencialmente ponderando el peso de los derechos o garantías fundamentales en juego. Lo difícil de ese emprendimiento lo destaca claramente Zagrebelsky: "La pluralidad de principios y la ausencia de una jerarquía formal entre ellos hace que no pueda existir una ciencia sobre su articulación, sino una prudencia en su ponderación. (...) Sin embargo, por muchos esfuerzos que las jurisprudencias constitucionales hayan hecho para formalizar los procedimientos lógicos de esta ponderación, los resultados (...) son desalentadores.”, y luego agrega el autor: “...es propio de los principios y de los valores su capacidad para relativizarse a fin de poder conciliarse recíprocamente." ZAGREBELSKY, ob. cit., p. 125. Sin embargo, esa tarea no es para nada sencilla. "En algunos casos, nuestros magistrados asumen los conflictos entre los principios y la necesidad del juicio de ponderación. Pero a veces se plantea ese conflicto, pero no asume la ponderación.”. SARLO, O., RODRÍGUEZ CARRAU, G., GÓMEZ LEIZA, J., FRANCOLINO, L., DELGADO, S., BURSTIN, D.: La era de los principios: entre compromiso moral y retórica vacía. FCU -Facultad de Derecho de la UdelaR, 2018. p. 135. 
- esto es, al proceso con todas las garantías- y a un proceso de duración razonable o sin las dilaciones indebidas. ${ }^{24}$

Según Bernal Pulido - en comentario a la obra de Alexy-: "La teoría de los principios no defiende la tesis de que dentro de los márgenes semánticos de los derechos fundamentales existe una Constitución plena, coherente y determinada, ni que ella prescribe una respuesta correcta para cada caso. Una parte importante de la teoría de los principios es la dogmática de los márgenes de acción. (...) Las disposiciones de derechos fundamentales no ordenan ni prohíben nada en relación con muchos casos posibles. Pues bien, en donde la Constitución nada prescribe, el Legislador tiene competencia para decidir."25

En definitiva, ambos sistemas son, a priori, posibles, válidos, a nivel de la legislación procesal. El sistema podrá inclinar su diseño a la consagración de cargas de colaboración con consecuencias procesales negativas para el caso de no adoptarse determinadas conductas, u optar por la regulación de deberes procesales de colaboración, con medidas de conminación, astricción o con sanciones para el caso de incumplimientos.

\section{La colaboración procesal en materia probatoria, con énfasis en la prueba pericial}

\section{1.- Reseña de derecho comparado.}

Son varios los ordenamientos jurídicos que han ido profundizando en la regulación de la colaboración procesal en general y respecto de la materia probatoria en particular. ${ }^{26}$

$24 \quad$ Destaca el autor citado que el conflicto que "se encuentra latente en todos los supuestos de infracción de las reglas de la buena fe procesal (...) sólo puede resolverse atendiendo a las particularidades de cada caso concreto, por lo que toda solución apriorística resulta inadecuada". PICÓ I JUNOY, El principio de la buena fe, ob. cit., pp. 36-37. Sin perjuicio de lo anterior, considero que la normativa sí podría ofrecer respuestas más claras, y una técnica procesal legislativa más depurada, en cuanto a la imposición de sanciones o consecuencias procesales negativas, frente a la "infracción" o el incumplimiento de las reglas de colaboración. 25 BERNAL PULIDO, C.: "Estudio introductorio". En: ALEXY, R., Teoría de los derechos fundamentales, traducción y estudio introductorio de BERNAL PULIDO, C., segunda edición. Centro de Estudios Políticos y Constitucionales, Madrid, 2012, pp. LII-LIII. 26 Aquí se incluirán referencias, básicamente, a la legislación procesal civil. No obstante, muy interesantes disposiciones también se pueden ubicar en cuerpos dedicados al proceso penal, como, por ejemplo, el art. 320 del CPP de Chile: "Instrucciones necesarias para el trabajo de los peritos. Durante la etapa de investigación o en la audiencia de preparación del juicio oral, los intervinientes podrán solicitar del juez de garantía que dicte las instrucciones necesarias para que sus peritos puedan acceder a examinar los objetos, documentos o lugares a que se refiriere su pericia o para cualquier otro fin pertinente. El juez de garantía accederá a la solicitud, a menos que, presentada durante la etapa de investigación, considerare necesario postergarla para proteger el éxito de ésta.". 
A modo de breve reseña de dichas regulaciones podemos referir, en primer lugar, al caso de Brasil. De la regulación brasileña se destacan las siguientes disposiciones del Código de Proceso Civil, aprobado como Ley $\mathrm{N}^{\circ}$ 13.105, el día 16 de marzo de 2015. Con carácter general, el art. 6, establece que: "Todos os sujeitos do proceso devem cooperar entre si para que se obtenha, em tempo razoável, decisão de mérito justa e efetiva.". Luego, ya en sede de disposiciones generales sobre prueba, el art. 378 va más allá y prevé que nadie se puede eximir o exonerar de dicho deber de colaboración: "Ninguém se exime do dever de colaborar com o Poder Judiciário para o descobrimento da verdade.".

El CPC brasileño distingue entre el alcance de la colaboración que se requiere a la parte, de aquella que se solicita a terceros. En ese sentido, su art. 379 dispone: "Preservado o direito de não produzir prova contra si própria, incumbe à parte: (...) II - colaborar com o juízo na realização de inspeção judicial que for considerada necessária..."; mientras que su art. 380 establece: "Incumbe ao terceiro, em relação a qualquer causa: (...) II - exibir coisa ou documento que esteja em seu poder. Parágrafo único. Poderá o juiz, em caso de descumprimento, determinar, além da imposição de multa, outras medidas indutivas, coercitivas, mandamentais ou subrogatórias.”.

Con relación a la prueba pericial ello se complementa con lo previsto en el art. 473 in fine del CPC en tanto allí se prevé que, para el desempeño de su función, el perito se puede valer de todos los medios necesarios, escuchando a testigos, obteniendo informaciones, solicitando documentos que estén en poder de la parte, de terceros, o en oficinas públicas.

En Colombia, por su parte, el Código General del Proceso de ese país - Ley $\mathrm{N}^{\circ} 1564$ de 2012 y modificativas-, incluye entre los deberes de las partes y sus apoderados el colaborar en la práctica de las pruebas y diligencias - art. $78 \mathrm{~N}^{\circ} 8$-. El art. 227 del CGP colombiano, en tanto, refiere, con carácter genérico, a la colaboración que deban prestar las partes y terceros en la práctica de la prueba pericial.

Muy interesante resulta el art. 233 del citado código: "Deber de colaboración de las partes. - Las partes tienen el deber de colaborar con el perito, de facilitarle los datos, las cosas y el acceso a los lugares necesarios para el desempeño de su cargo; si alguno no lo hiciere se hará constar así en el dictamen y el juez apreciará tal conducta como indicio en su contra. Si alguna de las partes impide la práctica del dictamen, se presumirán ciertos los hechos susceptibles de confesión que la otra parte pretenda demostrar 
con el dictamen y se le impondrá multa de cinco (5) a diez (10) salarios mínimos mensuales. Parágrafo. El juez deberá tener en cuenta las razones que las partes aduzcan para justificar su negativa a facilitar datos, cosas o acceso a los lugares, cuando lo pedido no se relacione con la materia del litigio o cuando la solicitud implique vulneración o amenaza de un derecho propio o de un tercero.".

En España, y sin perjuicio de otras disposiciones de interés, el art. 328 de la LEC 1/2000 prevé un "Deber de exhibición documental entre partes", aunque sin una sanción para el caso de incumplimiento. Se puede entender que no se trata de un verdadero deber procesal, a poco que se analiza el siguiente art. 329 de la citada LEC 1/2000, en donde se regulan no ya sanciones, sino los "Efectos de la negativa a la exhibición" - expresión genérica bajo la que se prevén los efectos que tiene la conducta de no colaboración en ese supuesto particular-.

Sin embargo, no se puede obviar, por cierto, que en el art. 288 de la LEC $1 / 2000$ se establecen también con carácter general "Sanciones por no ejecución de la prueba en el tiempo previsto", disponiéndose que el litigante por cuya causa no se ejecutare temporáneamente una prueba admitida será sancionado por el tribunal con multa que no podrá ser inferior a 60 euros ni exceder de 600 euros - claro que puede ser discutible la aplicación de dicha sanción a la exhibición de documentos en poder de la contraparte, cuando la consecuencia prevista específicamente en el art. 329 de la LEC 1/2000 no incluye la alusión a multas-.$^{27}$

27 Ahora bien, más allá de la regulación general a la que se acaba de hacer mención, vale reconocer que la LEC $1 / 2000$ se ha visto modificada a partir de lo dispuesto en el R.D.ley $9 / 2017$, de 26 de mayo - por el que se transponen directivas de la Unión Europea en los ámbitos financiero, mercantil y sanitario, y sobre el desplazamiento de trabajadores-, para incluir normas para el acceso a las fuentes de prueba en procedimientos de reclamación de daños por infracción del derecho de la competencia. En ese sentido, en su art. 283 bis, letra g) refiere ahora a la "Ejecución de la medida de acceso a fuentes de prueba", estableciendo, en lo que aquí más interesa, que: “...2. El tribunal empleará los medios que fueran necesarios para la ejecución de la medida acordada y dispondrá lo que proceda sobre el lugar y modo en el que haya de cumplirse. En particular, cuando la medida acordada consista en el examen de documentos y títulos, el solicitante podrá acudir asesorado por un experto en la materia, que actuará siempre a su costa. 3. De ser necesario podrá acordar mediante auto la entrada y registro de lugares cerrados y domicilios, y la ocupación de documentos y objetos que en ellos se encuentren...". Luego, en el art. 283 bis, letra h), prevé una multiplicidad de consecuencias ante la obstrucción a la práctica de las medidas de acceso a fuentes de prueba, a cuya lectura remito. 
Finalmente, en Uruguay, se debe estar a lo dispuesto, básicamente, en los arts. 5, 142, 189, 191 del CGP, siendo particularmente relevante la reforma del año 2013 que permite exigirle a los sujetos del proceso la máxima colaboración para la realización de todos los actos procesales reforma introducida a los arts. 5 y 142 del CGP por el art. 1 de la Ley $\mathrm{N}^{\circ}$ 19.090, de 14 de junio de 2013-. ${ }^{28}$

Nuevamente, lo que evidencia la reseña de derecho comparado es que la colaboración procesal se puede manifestar en diversos momentos del proceso, pero que en la prueba adquiere especial significación, ya que, como recuerda Pereira Campos, con referencia a la opinión de Devis Echandía: "Si la prueba es común, si tiene su unidad y su función de interés general, no debe usarse para ocultar o deformar la realidad, para tratar de inducir al juez a engaño...". ${ }^{29}$

\section{2.- Elenco de conductas de colaboración.}

28 El CGP uruguayo hace mención a la máxima colaboración para la realización de todos los actos procesales, sin embargo, ello trasluce un concepto jurídico de difícil determinación - en cuanto al alcance de lo que es o debe ser la "máxima" colaboración-, por lo que su apreciación dependerá, en gran medida, de las circunstancias del caso. Antes de la Ley $\mathrm{N}^{\circ} 19.090$ el Código no incluía una referencia general a la máxima colaboración para la realización de los actos procesales, de parte de todos los sujetos del proceso - existían referencias puntuales en sus arts. 189 y 191-. Sin embargo, algunos ya entendían, por esas y otras disposiciones, que existía un principio de lealtad, probidad y buena fe en materia de prueba. Entre otros, KLETT, S.; BALUGA, C.; ÁLVAREZ, F.; CASTILLO, J.: "Principios de la prueba en el sistema procesal civil". En: Revista Uruguaya de Derecho Procesal, 1/2000. pp. 95-ss. Como referencia al análisis de los arts. 5 y 142 del CGP, en la redacción dada por el art. 1 de la Ley $\mathrm{N}^{\circ} 19.090$, ver los completos aportes y diferentes puntos de vista en VALENTIN, G.: La reforma del Código General del Proceso. FCU, Montevideo, 2014. pp. 11-15, 107-109 y KLETT, S.: Proceso ordinario en el Código General del Proceso, Tomos I y II. FCU, Montevideo, 2014. pp. 39-41 y pp. 150-158 (respectivamente). Asimismo, puede resultar interesante, con derivaciones un tanto difusas y consecuencias no del todo precisas, el trasladar el concepto de máxima colaboración a lo que es la "máxima" colaboración del propio tribunal -que también es un "partícipe" del proceso-. Aunque no será analizado en el presente trabajo, se podría pensar en supuestos en los que la colaboración al perito se la debe brindar el tribunal. A modo de ejemplo, casos en los que la colaboración se materialice en cuestiones que pueden resultar banales, pero a la larga relevantes, como el facilitar y no obstaculizar por parte de la oficina judicial el acceso del perito al expediente y demás actuaciones procesales que puedan servir de insumo a la labor, el procurar -si fuera del caso- que se sustancien sin dilaciones cuestiones accesorias o incidentales como el pago de honorarios a peritos designados judicialmente, etc.

PEREIRA CAMPOS, “Moralidad, veracidad y colaboración”, ob. cit., p. 279. 
Ya en su momento, y desde la perspectiva del perito o experto, Devis Echandía vinculó el derecho del perito a la libertad en el desarrollo de su investigación -naturalmente, dentro de los límites del encargo o de las instrucciones que le fueran impartidas en el proceso-, con el derecho del perito a exigir que se le suministren los medios indispensables para la realización de esta. ${ }^{30}$

Lo expuesto por Devis Echandía es compartido por Pereira Campos en el entendido que las partes tienen que facilitarles a los peritos los medios para realizar sus estudios, siempre que les sea posible hacerlo, y cuando obstaculizan la labor de éstos o se niegan a permitir sus exámenes e impiden que el dictamen se rinda, incurren en una conducta anti-procesal y desleal. ${ }^{31}$

Resulta complejo pronunciarse en detalle respecto del alcance de ese derecho a exigir los medios indispensables para la efectivización de la investigación o sobre la posible conducta procesal de las partes o terceros ante los requerimientos de los peritos, pero sin duda todo ello es relevante en el plano práctico-forense, donde las discusiones pueden ser muchas y de diverso tenor. ${ }^{32}$

Cabe consignar que la colaboración se le prestaría tanto al perito como, eventualmente, a sus auxiliares, si el ordenamiento jurídico que se esté considerando le reconoce al perito la posibilidad de valerse del concurso de otras personas. ${ }^{33}$

A continuación, se ofrecen algunos ejemplos de conductas de colaboración vinculadas a la práctica de la prueba pericial, sin que -por supuesto- se agote el elenco de supuestos posibles. ${ }^{34}$

30 DEVIS ECHANDÍA, H.: Teoría general de la prueba judicial, Tomo II, quinta edición. Víctor P. de Zavalía-Editor, Buenos Aires, 1981. p. 376.

31 PEREIRA CAMPOS, "Moralidad, veracidad y colaboración”, ob. cit., p. 280.

32 Véase, a modo de ejemplo, para casos de responsabilidad civil médica, BARBOSA MOREIRA, J.C.: "La negativa de la parte a someterse a la pericia médica". En: Revista Uruguaya de Derecho Procesal, 1/2003. pp. 13-17.

33 VESCOVI, E. (Director); DE HEGEDUS, M.; KLETT, S.; CARDINAL, F.; SIMÓN, L. M.; PEREIRA, S.: Código General del Proceso. Comentado, anotado y concordado, Tomo 5. Ábaco, Buenos Aires, 1998. p. 322.

34 Cabe consignar, una vez más, que las conductas concretas podrán variar en función, básicamente, de dos parámetros a considerar: uno, la determinación del alcance de la colaboración - en particular, su regulación como carga o como deber procesal-, y dos, el tipo de prueba pericial que se recoge en cada ordenamiento jurídico - en especial, pericia de parte y/o pericia basada en la designación judicial-. 


\subsection{Colaboración desde el inicio. La delimitación de los puntos u objeto de la pericia:}

Una forma de contribuir al éxito en la producción o diligenciamiento de la prueba pericial es que los temas objeto de análisis sean planteados y definidos con precisión por las partes y sus abogados, lo que le permitirá al perito o experto comprender, en sus justos términos, el alcance de la solicitud, requerimiento o encargo que se le ha efectuado. ${ }^{35}$ De ese modo, las partes facilitarán la tarea pericial si realizan solicitudes con objeto preciso, claro, marcando las interrogantes concretas sobre las que resulta conveniente o necesario la introducción del conocimiento extrajurídico.

Esto eventualmente presentará algunas dificultades prácticas para la parte que requiere de la incorporación del conocimiento extrajurídico al proceso, cuando no cuenta con asesoramiento técnico previo. Al menos así sucederá en temas técnico-científicos complejos o en los que se requiera un análisis de ciertas cuestiones muy específicas o concretas. Asimismo, se pueden plantear problemas en lo que refiere a la selección de la especialidad o subespecialidad del perito, lo que también tiene relación con el objeto de la pericia - por ejemplo, en el caso en que se encuentre disociado el objeto de la prueba pericial con la especialidad o subespecialidad del perito que debe realizar el encargo-. Sería conveniente relevar la especialidad del perito en la oportunidad de controlar la admisibilidad de la prueba, en pos de la economía procesal y la correcta programación de las futuras actividades procesales. ${ }^{36}$

En algunos casos, luego de designado, el perito también podrá requerir de las partes -en particular, cuando cumple su encargo o labor pericial fruto de una designación judicial- que se le aclare alguno de los puntos objeto de peritación. Las deficiencias que puedan existir en la delimitación del objeto concreto de esta prueba no podrán, luego, ser atribuidas al perito. ${ }^{37}$

35 Picó i Junoy menciona como un ejemplo de buena fe de los litigantes respecto de la regulación de la prueba pericial -aquí no sería propiamente un caso de colaboración-, el caso del aporte de dictámenes de peritos privados o de parte, señalando que se debe aportar al inicio del proceso o, indicar, la aportación posterior si no fuere posible acompañarlos en ese primer momento. PICÓ I JUNOY, El principio de la buena fe, ob. cit. p. 186.

36 Como indican Vescovi et alii: “....resulta conveniente especificar la materia propia de la pericia a los efectos de evitar dudas posteriores, sobre todo en temas que pueden conducir a una interpretación ambigua, por pertenecer a campos científicos, técnicos, artísticos afines p. ej., las materias siquiátrica y sicológica-." VESCOVI, E. (Director); DE HEGEDUS, M.; KLETT, S.; CARDINAL, F.; SIMÓN, L. M.; PEREIRA, S., ob. cit., p. 313.

$37 \quad$ Sin perjuicio de compartirse que, en aquellos puntos en los que el perito se hubiese extralimitado del objeto, el dictamen no puede ser tomado en consideración. Véase sentencia de 


\subsection{Colaboración para la preservación de la imparcialidad del perito.}

La finalidad perseguida es que el perito cumpla su encargo de la manera más independiente, imparcial y objetiva posible, al menos desde el punto de vista ético y jurídico. ${ }^{38}$ Los temas éticos y jurídicos vinculados con la independencia, imparcialidad $\mathrm{y}$, también, con los conflictos de interés, requieren de la colaboración de las partes y de terceros y se relacionan con la lealtad, probidad y buena fe.

la Sala $1^{\text {a }}$ del Tribunal Supremo español, $n^{\circ} 785 / 2010$, de 25 de noviembre, citada en SALAS CARCELLER, A.: "La prueba pericial civil en la doctrina del Tribunal Supremo". En: Picó I Junoy, J.y De Miranda Vázquez, C.: Peritaje y prueba judicial. Bosch Editor, Barcelona, 2017. p. 40.

38 Ese concepto de imparcialidad u objetividad refiere más a lo jurídico que a lo científico, técnico o artístico; de lo contrario, sería olvidar que los expertos pueden pertenecer a distintas comunidades -siendo, incluso, algunas más relevante que otras-, se pueden encontrar 'afiliados' a cierta corriente o posición en su respectivo campo de actuación académico, todo lo cual no les permite abstraerse totalmente de esos factores que pueden, y seguramente así lo hagan, terminar incidiendo en sus conclusiones para el caso concreto. Es más, incluso dentro de una misma "comunidad" puede no existir consenso, por el carácter "parlamentario" de la ciencia del que hablan Sozzo y Berros: “...no se ha dado debida cuenta dentro del campo jurídico del carácter parlamentario que asumen las ciencias ante cuestiones complejas en las que campea un marco de incerteza o controversia científica y de qué modo canalizarlo en la regulación de las pericias. Actualmente, no hay obligación alguna por parte de los peritos de presentar un 'cuadro controversial' completo, en el cual se dé cuenta de las diversas posturas respecto del problema analizado, así como, tampoco, de la posición que ellos asumen para sí. De este modo, la parlamentariedad científica, no es advertida por la normativa que regula las pericias. No se considera que pueda un juez apartarse de la pericia en razón de considerar el panorama completo de producción de conocimiento que arroje un esquema de controversia o incerteza científica, respecto del tema que llega a su conocimiento. Por el contrario, la forma de relacionamiento que guarda el conocimiento experto con el juez o tribunal, puede ser adscripta a la idea moderna de que el derecho constituye un modo de conocimiento reflejo. Una deconstrucción de este tipo de articulación entre pericias y decisión judicial exige dar cuenta del modo contemporáneo de producción del conocimiento para poder luego sí repensar la regulación del trabajo experto en el proceso y más en general rever el modo de relación que en el marco del proceso judicial se entabla entre conocimiento experto y saber legal, de modo de permitir garantizar la autonomía de ambos y el posterior debate democrático sobre la decisión.". SOZZO, G., BERROS, M.: "Una agenda para el principio precautorio". En: Revista Crítica de Derecho Privado, No 6, Año 2009. pp. 763-793. Determinar la extensión de una comunidad científica, su relevancia y sus consensos trae consigo otras tantas dificultades. Con mayor profundidad, para el análisis de la imparcialidad, la prueba científica y la ciencia, véase: SOBA BRACESCO, I. M.: Relación de causalidad y prueba pericial. La Ley Uruguay, Montevideo, 2016. pp. 213-221 y pp. 240-262. Respecto de la existencia de un consenso general de la comunidad científica interesada, como parte de los criterios del caso Daubert vs. Merrell Dow Pharmaceuticals, Inc. (Corte Suprema, EE.UU., 1993), véase, entre varios más, TARUFFO, La prueba, ob. cit., p. 283. 
Nieva-Fenoll señala que: "Aunque pocas veces se han puesto por escrito, existen historias reales de peritos de designación judicial que, una vez nombrados, son telefoneados a la carrera por los abogados de las partes para proponerles cobrar más dinero si les hacen el dictamen a su favor. (...) Con los dictámenes de parte sucede esencialmente lo mismo. Ningún dictamen de parte es presentado sin antes haber sido revisado y adaptado profundamente por el abogado...". ${ }^{39}$

Es que todo esto impacta en la realización del dictamen pericial y hace a la conformación de las condiciones epistemológicas necesarias que debe reunir el experto para poder brindar la mejor explicación posible en el proceso jurisdiccional. ${ }^{40}$

Es esperable, también, que las partes pongan de manifiesto aquellos conflictos de interés de los peritos que son de su conocimiento o aquellas situaciones que pueden afectar la imparcialidad de dichos peritos y que sean, o deban ser, de su conocimiento. Se exige, por supuesto, que dichas manifestaciones, que pueden llegar a menoscabar la consideración profesional del perito, se formulen de forma motivada. ${ }^{41}$ Por ejemplo, que se trata de un perito o experto que tuvo una relación profesional muy extensa con una de las partes y que se jubiló recientemente, o que se encuentra de algún modo todavía vinculado por algún tipo de obligación contractual, o que se trata de un perito que es trabajador dependiente o que presta servicios profesionales a una de las partes.

Dependiendo del sistema de prueba pericial que se hubiese adoptado, estos conflictos de interés o situaciones que afectan la imparcialidad podrían dar lugar a supuestos de abstención, excusación y/o recusación de los peritos, algún tipo de tacha o de circunstancia a ser tomada en cuenta como motivo de sospecha en la valoración. Se insiste, ello dependerá del sistema de prueba pericial diseñado en cada caso: esto es, un sistema de

39 NIEVA-FENOLL, J.: "Repensando Daubert: elementos de convicción que debe tener un buen dictamen pericial”. En: Picó I Junoy, J. y De Miranda Vázquez, C.: Peritaje y prueba judicial, Bosch Editor, Barcelona, 2017, p. 95.

40 Esto es particularmente relevante, y así se ha entendido a nivel doctrinario y jurisprudencial. Por ejemplo, se ha señalado que: “... 'existe una conexión directa entre imparcialidad y verdad' de modo que la imparcialidad no es sólo una exigencia ética sino también una condición epistemológica para buscar la verdad con la mayor objetividad (Taruffo, Michele. Simplemente la verdad. El juez y la construcción de los hechos. Madrid, 2010, p. 138)...". Tribunal de Apelaciones en lo Civil de $1^{\circ}$ Turno (Uruguay), sentencia ${ }^{\circ}$ 34/2012, de 21 de marzo de 2012 - discordia al fallo de Alicia Castro-.

41 PICÓ I JUNOY, El principio de la buena fe, ob. cit., p. 188. 
prueba pericial de parte, un sistema de prueba pericial designada por el tribunal - a pedido de parte o de oficio-, o un sistema mixto - que permite o habilita ambos tipos de pericias- ${ }^{42}$

Aunque puede parecer infrecuente, no por ello se debe dejar de advertir que las partes también deberán respetar la imparcialidad del perito luego de la selección del experto por la parte o con posterioridad a la designación judicial del mismo, evitando incurrir en conductas que pudieran afectar dicha imparcialidad. Se piensa aquí en conductas de diferente tenor o gravedad, que pueden consistir, por ejemplo, en la presión, hostigamiento y/o coacción al perito o personas cercanas o allegadas, en instituciones $\mathrm{u}$ organizaciones de las que este forme parte, o en ofrecimientos de determinadas ventajas laborales o profesionales, en la financiación la actividad académica o de investigación del experto, etc.

\subsection{Colaboración de los abogados de las partes con el perito.}

¿Pueden los peritos reunirse con los abogados de las partes? Obviamente la pregunta tiene sentido, principalmente, en sistemas en los que los peritos son designados judicialmente, ya que, en los casos de pericias de parte, el perito normalmente se reúne con el abogado que le efectúa el encargo - es más, el abogado que no lo hiciere podría ser tachado de negligente por su cliente-.

En el caso de las pericias judiciales, no se ha encontrado -en el derecho comparado relevado- ninguna prohibición en ese sentido. ${ }^{43}$ Sí se regula el procedimiento de producción de la prueba pericial, el que -según el sistema

42 En el caso del Código General del Proceso colombiano, en el que se admite la pericia de parte, expresamente se indica en su art. 235 que las partes se abstendrán de aportar dictámenes rendidos por personas en quienes concurre alguna de las causales de recusación establecidas para los jueces, pero también se aclara que "No se entenderá que el perito designado por la parte tiene interés directo o indirecto en el proceso por el solo hecho de recibir una retribución proporcional por la elaboración del dictamen. Sin embargo, se prohíbe pactar cualquier remuneración que penda del resultado del litigio.”.

43 Manifiesta Orellana de Castro que tampoco ha encontrado una prohibición de ese tenor -sin perjuicio de lo que indican los principios generales como los de independencia, lealtad, objetividad, etc.-en las normas deontológicas de Colegios o Asociaciones profesionales que ha consultado. No obstante, indica que esas cuestiones deberían formar parte de un Estatuto jurídico de los peritos designados judicialmente. ORELLANA DE CASTRO, R.: "Un estudio crítico sobre los diferentes sistemas de designación de peritos y sobre las listas de peritos de la LEC”. En: Picó I Junoy, J. y De Miranda Vázquez, C.: Peritaje y prueba judicial. Bosch Editor, Barcelona, 2017. p. 119. 
considerado y las circunstancias del caso y del objeto a periciar- podrá ser fuera de audiencia o en audiencia.

Son muy interesantes e ilustrativas las interrogantes que se plantea Orellana de Castro sobre esta temática: “¿La relación que entabla el perito designado por el tribunal con el abogado que ha pedido esta prueba con el fin de solicitar información adicional que le ayude a elaborar el dictamen, debería hacerse a través del tribunal pueda (sic) hacerse de forma directa y dando conocimiento a las partes personadas? ¿Podría el perito designado judicialmente adelantar la conclusión de su dictamen al abogado que ha solicitado su informe, antes de emitir o entregarlo ante el tribunal? ¿Podría el perito incorporar a su dictamen aquellas sugerencias que pueda haberle trasladado el abogado durante el proceso de elaboración de su estudio pericial, siempre que aquel esté de acuerdo con las mismas y que no afecten ni modifiquen su conclusión?". ${ }^{44}$

Considero que el perito tendría que plantear la situación a nivel procesal y advertir que se le ha solicitado una entrevista por parte de uno de los abogados o que él requiere de una reunión, a efectos de actuar lealmente y de transparentar de ese modo la situación y, eventualmente - podría por supuesto no llegar a presentarse la situación-, evitar que lo que se le formule en la entrevista con el abogado sea un mero alegato a favor de una de las teorías del caso o, peor aún, en casos patológicos, una amenaza de cualquier tipo a la imparcialidad del experto. ${ }^{45}$

Como ya se ha dicho, las aclaraciones que necesite el perito con relación a aspectos confusos o imprecisos del encargo que se le ha efectuado, sería conveniente efectuarlas en el proceso, para que todas las partes estuvieran advertidas de lo que sucede en el caso concreto.

\subsection{Colaboración en el acceso o exhibición de documentos.}

La regulación colombiana, como se ha visto, prevé en el art. 233 del CGP que las partes tienen el deber de colaborar con el perito, de facilitarle los datos, las cosas y el acceso a los lugares necesarios para el desempeño de su cargo. El art. 473 in fine del CPC brasileño, por su parte, prevé que

$44 \quad$ Ibídem, p. 119.

$45 \quad$ Véase, en el apartado dedicado al cuidado y la preservación de la imparcialidad del perito, las referencias a la no corrupción del experto, en NIEVA-FENOLL, ob. cit., pp. 94-95. Asimismo, esta sería la solución que se extrae del sistema procesal civil francés, la cual procura se respete el principio de contradicción en la ejecución de la prueba pericial. ORELLANA DE CASTRO, ob. cit., p. 120. 
los peritos puedan solicitar documentos que estén en poder de la parte, de terceros, o en oficinas públicas.

En ese sentido, la Ley de Enjuiciamiento Civil española, 1/2000, en su art. 336, bajo el nomen iuris de "Aportación con la demanda y la contestación de dictámenes elaborados por peritos designados por las partes”, establece lo siguiente: “(...) 5. A instancia de parte, el juzgado o tribunal podrá acordar que se permita al demandado examinar por medio de abogado o perito las cosas y los lugares cuyo estado y circunstancias sean relevantes para su defensa o para la preparación de los informes periciales que pretenda presentar..." - texto introducido por el apartado cuarenta y uno del artículo único de la Ley 42/2015, de 5 de octubre, de reforma de la LEC-. ${ }^{46}$

Devis Echandía, a modo ilustrativo, ya se mostraba partidario, en su momento, de otorgarle al juez “... las más amplias facultades para obtener la exhibición coactiva de documentos o cosas muebles y realizar inspecciones o reconocimientos de inmuebles, sin perjuicio de la imposición de multas, de la indemnización de perjuicios por la parte culpable y de la presunción de ser ciertos los hechos objeto de la prueba, cuando se trate de una de las partes, con las salvedades del respeto al secreto profesional (...) y de la reserva legal expresamente consagrada.". ${ }^{47}$

Una dificultad especial puede ocurrir cuando, por ejemplo, los documentos que se necesita examinar - v.gr., historia clínica, estados financieros, documentación contable de una empresa, etc.-, no forman parte de la prueba del proceso, o su agregación, intimación o exhibición no fue previamente solicitada - en el momento procesal oportuno-.

Piénsese, por ejemplo, en un caso de responsabilidad médica, donde reclaman los padres por los daños generados a su hijo y, además, por daño propio. El hecho es que el niño habría sufrido determinadas complicaciones en el parto, lo que le generó severos daños. En ese proceso se encuentra agregada la historia clínica del niño, incluyéndose allí la ficha obstétrica, relativa al parto, mas no se encuentra la historia o registro médico de la

$46 \quad$ Picó i Junoy señala que la LEC exige a las partes la buena fe para la práctica de ambos tipos de pericia (la privada o de parte y la efectuada por un permito designado judicialmente); ello implica que deban permitir el acceso del perito al objeto sobre el cual efectuará su dictamen. PICÓ I JUNOY, El principio de la buena fe, ob. cit., pp. 186-187. Sobre la modificación introducida por la Ley $42 / 2015$ de 5 de octubre, véase: PICÓ I JUNOY, J.: "Quince años de prueba pericial: problemas y soluciones". En: Picó I Junoy, J. y De Miranda Vázquez, C.: Peritaje y prueba judicial. Bosch Editor, Barcelona, 2017. pp. 79-80. 
madre. El perito designado judicialmente en el expediente pide el acceso a dicha historia clínica, pues considera relevante conocer datos de salud de la madre, en particular, cómo fue el embarazo. Una actitud colaborativa indica que se debe permitir incorporar dicha historia clínica para el análisis del perito, ${ }^{48}$ pues el experto debe contar con el material o los insumos necesarios para formular su dictamen y emitir su opinión - lo que hace a la efectiva o adecuada colaboración en el diligenciamiento de la prueba pericial-. Entiendo, por tanto, que la cuestión radica allí, más que en la eventual discusión acerca de la iniciativa probatoria del tribunal - esto es, si el tribunal puede, sin solicitud previa de las partes, o frente a la negativa de estas, franquear al perito el acceso a determinados documentos, o como se analizará en el apartado siguiente, o recibir la declaración de determinadas personas-. Sin perjuicio de lo que se disponga en materia de iniciativa probatoria del tribunal, se debe estar, en primer término, a las normas sobre colaboración en la práctica de un medio de prueba que sí fue solicitado, admitido y dispuesto en el proceso - en el caso, la prueba pericial-.

Asimismo, las partes o los terceros tendrán la carga, o en su caso el deber, de dar su consentimiento para eliminar barreras u obstáculos de acceso a la documentación y/o información, siempre que no exista un motivo fundado o justificado, para negar dicho consentimiento.

El derecho de defensa no puede ser un obstáculo para acceder a información que no reviste la calidad de secreta, reservada y/o confidencial. Si existiera alguna de esas causales para negar dicha información, la parte se podrá negar lícitamente, lo que deberá ser apreciado por el tribunal en el caso concreto. ${ }^{49}$

$48 \quad$ El caso es obtenido de la práctica forense, comentado por un colega que se dedica a responsabilidad civil médica, y que representa a una Institución Médica. En ese proceso judicial se permitió, sin objeciones de las partes, el acceso a la historia clínica.

49 En ese sentido, véase, las referencias de Marinoni y Cruz Arenhart a las reglas que permiten excluir el deber de colaboración, entre las que incluyen expresamente al deber de confidencialidad: MARINONI y CRUZ ARENHART, ob. cit., pp. 164-167. Con relación al derecho a presentar medios de prueba relevantes y el conflicto de valores que se podría presentar, por ejemplo, cuando se sacrifica el derecho a presentar pruebas relevantes en favor de la protección de valores o intereses extraprocesales, como en el caso de privilegios profesionales o comerciales, se puede recurrir a Taruffo, quien señala que esos casos se deberían reducir a unos pocos: “...en general, sólo la protección de otro derecho constitucional o fundamental más importante podría justificar -tras la debida consideración por parte del tribunal- que se sacrificara el derecho a la prueba. Siempre que sea posible se deberían establecer mecanismos especíicos con el fin de proteger secretos relevantes sin eliminar los derechos procesales de las partes y los principales valores vinculados con la búsqueda de la verdad.". TARUFFO, La prueba, ob. cit., pp. 57-58. 
También a los terceros se le puede requerir la colaboración con la producción de la prueba pericial, e incluso aplicar medidas de coerción, astricción y/o multa. ${ }^{50}$

No obstante, como todo requerimiento de colaboración, el mismo se deberá ejecutar en base a criterios de precisión y razonabilidad. No es igual, para ejemplificar, que se solicite a un tercero que realice una búsqueda de miles de documentos en varios años, para lo cual -sino se cuenta con registros o sistemas informatizados- se debería contar con la labor de varias personas para dar respuesta satisfactoria a la solicitud, que se circunscriba la búsqueda lo más posible a aquello que resulta verdaderamente relevante para el proceso y para la pericia, y que no pudo ser conseguido de otro modo menos gravoso.

Asimismo, si dicha colaboración causare gastos u otro tipo de menoscabo patrimonial a los terceros, parece lógico que se consigne o pague por los gastos o se los indemnice de algún modo (en el caso uruguayo, por ejemplo, surge del art. 189.2 del CGP que las cantidades que las partes habrán de abonar a título de indemnización se fijarán por el tribunal con carácter irrecurrible). ${ }^{51}$ Igualmente, considero que sería útil reflexionar también acerca de qué sucede en los casos en los que la colaboración se solicita a una de las partes - no ya a terceros-, pues se podría estar ante situaciones verdaderamente gravosas.

Como posibles soluciones se podría pensar, de lege ferenda, entre otras, en las siguientes: i) que se fije por parte del tribunal, para el caso concreto, quién debe asumir los gastos derivados de la colaboración, independientemente de quien tenga que asumir el pago de los gastos $\mathrm{u}$ honorarios del perito; ii) que los gastos de la colaboración los asuma quien tiene que afrontar el costo de la labor pericial; iii) que se rija el punto por el régimen general que cada ordenamiento prevé en materia de costas y costos del proceso correspondiente.

50

A modo ilustrativo, CGP uruguayo, art. 189; CPC brasileño, arts. 378 y 380 punto II.

51 Es más, se ha dicho que corresponde prescindir de la diligencia si el tercero que debe colaborar demuestra que la práctica de la prueba puede acarrearle perjuicios significativos y las partes no consignan la suma fijada por el tribunal a tales efectos. VESCOVI, DE HEGEDUS, KLETT, CARDINAL, SIMÓN, PEREIRA, Código General del Proceso. Tomo 5, ob. cit., pp. 497-498. En similar sentido, refiriendo a algunos sistemas procesales como el húngaro y el portugués, indica Devis Echandía que: “...se reconoce el derecho a oponerse cuando pueda violarse un secreto profesional o causarse grave daño moral o patrimonial, y se da al tercero, que sufre perjuicios con la exhibición, el derecho a reclamar la indemnización de perjuicios.”. DEVIS ECHANDÍA, Teoría general de la prueba, ob. cit., p. 376. 


\subsection{Colaboración para la realización de entrevistas o exámenes por parte del perito.}

El perito puede que tenga la necesidad no ya de examinar cosas o documentos, o relevar información o datos en poder de una de las partes, sino que requiera, para una correcta elaboración de su dictamen, de la entrevista o examen personal de la parte o de un tercero.

En efecto, algo similar a lo que ya vimos en el apartado anterior respecto de documentos que no han sido previamente incorporados al expediente, también podría tener lugar si el perito requiere información de parte de una persona que no ha sido ofrecida como testigo - por ejemplo, uno de los médicos que participó de la atención sanitaria de una persona que ha iniciado una reclamación por responsabilidad médica; la persona encargada de los temas contables o financieros de una empresa en un proceso de tipo societario; el responsable del área de tecnológica de una empresa en la que se requiere la realización de una pericia de tipo informático; la persona encargada de recursos humanos, un jerarca o un compañero/a de trabajo en un caso vinculado a una situación de acoso dentro de una organización, etc.-.

Se entiende que dichas entrevistas o exámenes podrían ser muy útiles para cumplir con el objeto del encargo pericial, y por tanto ser necesarios para que no se frustre la prueba o la prueba no produzca un resultado inútil.

Por tanto, siempre que no exceda el objeto de la pericia o los puntos que le han sido consultados al experto, y que se respeten ciertas garantías - como por ejemplo, que se permita la presencia de las partes y/o sus asesores, a los efectos de facilitar el control-, se le tendría que permitir utilizar -como parte de su metodología de trabajo pericial (y de obtención de insumos o fuentes de conocimiento)- todo aquello que coadyuve con la exitosa elaboración y emisión del dictamen, informe o pronunciamiento que se le ha solicitado.

Vescovi et alii señalan -refiriendo a los estudios de Devis Echandía- que el perito podría solicitar el concurso de "...terceras personas de las cuales se puede recibir informes a los efectos de realizar la pericia; en tales casos, es necesario precisar que, si bien el perito puede aceptar declaraciones de terceros, las mismas deben realizarse, o bien en oportunidad de la práctica en sentido estricto -con los debidos controles de las partes-, o bien comunicar 
al tribunal, previamente, la necesidad de diligenciar tal medio, para que este lo haga en audiencia y con las garantías del debido proceso.". ${ }^{52}$

Algo similar indica Parra Quijano: "Una de las fuentes del testigo mencionado o referenciado es precisamente la que se da cuando los peritos están preparando el dictamen pericial y reciben informes respecto de personas que conocen los hechos sobre los cuales debe versar el dictamen; ellos harán constar en el acta del dictamen tal circunstancia y los nombres y el lugar en donde pueden ser citadas esas personas. El juez podrá ordenar (...) que sean citadas a rendir declaración..." ${ }^{53}$

El derecho comparado ofrece algunos textos de gran interés con relación a la entrevista o examen de personas. Sin perjuicio de las normas ya reseñadas, a modo ilustrativo, se destaca los arts. 231 y 232 del Código Civil brasileño - Ley $\mathrm{N}^{\circ} 10.406$, de 10 de enero de 2002-, vinculados a pericias médicas, en los que se prevé -respectivamente- lo siguiente: "Aquele que se nega a submeter-se a exame médico necessário não poderá aproveitar-se de sua recusa."; "A recusa à perícia médica ordenada pelo juiz poderá suprir a prova que se pretendia obter com o exame.". Sobre el punto, Marinoni y Cruz Arenhart han expresado: "Si la parte que tiene la carga de la prueba no puede ser perjudicada por el comportamiento negativo de la otra, la constatación de la negativa injustificada implica la admisión del hecho que la pericia estaba destinada a demostrar, mas no precisa ser probada por el titular de la carga...". ${ }^{4}$

Con relación al tema aquí planteado, otro ejemplo de derecho comparado es el del citado art. 336 de la LEC española 1/2000 - en redacción dada por Ley 42/2015, de 5 de octubre-, el cual prevé que: “...cuando se trate de reclamaciones por daños personales, podrá instar al actor para que permita su examen por un facultativo, a fin de preparar un informe pericial.".

En un caso de responsabilidad médica reseñado por Picó i Junoy se planteaba el problema de la falta de colaboración en los siguientes

52 VESCOVI, DE HEGEDUS, KLETT, CARDINAL, SIMÓN, PEREIRA, Código General del Proceso. Tomo 5, ob. cit., p. 323.

53 PARRA QUIJANO, J.: Manual de derecho probatorio, décimo tercera edición. Ediciones Librería del Profesional, Bogotá, 2002. p. 541.

54 MARINONI y CRUZ ARENHART, ob. cit., p. 209. Una situación diferente se puede suscitar cuando la negativa al examen proviene de un tercero, ajeno a la relación procesal. Los referidos autores plantean que nada impide que se obligue a un tercero a someterse a un examen médico, sin embargo -se preguntan- si sería posible extraer de su negativa injustificada un argumento de prueba, partiendo de la premisa que una persona extraña al proceso no tendría ningún interés en su resultado. ob. cit., pp. 210-213. 
términos: “...SAP de Barcelona (sec. 16 ) de 24 de mayo de 2004, en su f.j. $5^{\circ}(\ldots)$ destaca: 'Debe significarse que doña Cristina no puso repara alguno (como lo muestra que dejase fotografiar su torso desnudo) para que un médico de su elección examinara en abril-mayo de 2002 su cuerpo a fin de emitir el oportuno dictamen pericial. La imprescindible buena fe procesal a observar por todos los intervinientes en un proceso (art. 247.1 de la LEC) imponía que, en justa reciprocidad, la perjudicada demandante atendiese el requerimiento que recibió a finales de marzo de 2003 para presentarse en la consulta de la Dra. Ángeles a fin de propiciar el correspondiente dictamen de la parte demandada'...". ${ }^{55}$

Una problemática similar se aprecia respecto de la realización de pruebas de tipo biológico, genéticas, de ADN o similares, en especial en casos de investigación de paternidad o maternidad. A modo ilustrativo, en Colombia, el art. 386 de su CGP dispone que el juez ordenará -aún de oficio- la práctica de una prueba con marcadores genéticos de ADN o la que corresponda con los desarrollos científicos y advertirá a la parte demandada que su renuencia a la práctica de la prueba hará presumir cierta la paternidad, maternidad o impugnación alegada. Luego, se señala que en caso de practicarse la prueba el juez ordenará a las partes para que presten toda la colaboración necesaria en la toma de muestras.

En Perú, el art. 282 del Código de Procedimiento Civil, le permite al Juez extraer conclusiones en contra de los intereses de las partes atendiendo a la conducta en el proceso, particularmente en casos de falta de cooperación o colaboración u obstrucción en materia probatoria. Esa disposición ha sido referida por la Sala Civil Permanente de la Corte Suprema de Justicia de la República en sentencia de casación de 30 de marzo de 2017 - asunto $\mathrm{N}^{\circ} 1936-2016-{ }^{56}$ en la decisión de un caso vinculado a una petición de herencia, en el cual el demandado se había negado a someterse a una prueba de ADN dispuesta de oficio para determinar el eventual parentesco con la parte actora. La Corte consideró acreditada la filiación argüida por la actora y compartió la opinión acerca de que el demandado se había negado injustificadamente a la práctica de dicha prueba, lo que debía -se dijo- ser valorado de acuerdo con el art. 282 del CPC peruano.

En Uruguay, también para los procesos de investigación de paternidad o maternidad, no se prevé que se pueda imponer forzosamente la realización

$55 \quad$ PICÓ I JUNOY, El principio de la buena fe, ob. cit., p. 187.

56 Consultada en GACETA JURÍDICA (PERÚ): < http://www.gacetajuridica.com. pe/boletin-nvnet/ar-web/cas1936-2016-AREQUIPA.pdf> [16/10/2018]. 
del examen de ADN, pero se señala que: “...La no colaboración para su diligenciamiento sin causa justificada, será tenida como una presunción simple en su contra..." -Código de la Niñez y la Adolescencia, art. 204. ${ }^{57}$

En definitiva, que se le pueda imponer a la parte o a un tercero su participación en un examen o entrevista de tipo personal que requiera el perito a los efectos de la realización de la pericia dependerá de lo previsto por cada ordenamiento jurídico, puntualmente, de si se colocó al sujeto en posición de carga o de deber procesal.

\section{Conclusiones.}

Colaborar con el proceso, ya sea una parte o un tercero, contribuye a la realización de sus fines y, en definitiva, a que se pueda acceder a una tutela jurisdiccional de mejor calidad. En el caso de la parte, la colaboración se puede considerar integrando el estándar de buen litigante y el no cumplir con las conductas de colaboración, asumiendo una actitud pasiva o prescindente, puede derivar en consecuencias de diferente calibre, dependiendo de cada ordenamiento jurídico.

Habiendo relevado algunos sistemas procesales, se puede apreciar que unos conciben a la colaboración como una carga procesal, mientras que otros la tratan como un verdadero deber.

En aquellos que regulan la colaboración como una carga, la falta de colaboración podría derivar en una presunción - simple o relativa- en contra del litigante, teniendo por probado el hecho que se quería acreditar - por ejemplo, mediante la pericia-; mientras que en los sistemas que consideran la colaboración como un deber procesal, la ausencia de colaboración conduce a la aplicación de medidas de coerción, conminación y/o sanción de la conducta que se ha apartado del estándar.

Claro que, en ocasiones, dependiendo de la consecuencia procesal negativa que el legislador consagre, nos podemos enfrentar a una cuestión de gradualismo, pues esas consecuencias procesales negativas - que se asocian con las cargas- pueden condicionar de tal modo, en la práctica, la libertad de actuar del sujeto que, en esencia, se podría considerar que se trata de verdaderas sanciones.

$57 \quad$ Una vez más, se aclara que en el presente trabajo no se incluyen referencias a la regulación específica del tema en el proceso penal, en el que se ha debatido también acerca de la realización compulsiva de las pruebas biológicas y/o de $\mathrm{ADN}$. 
En cualquier caso, la aplicación de sanciones en el ámbito procesal debería surgir de normas expresas que indiquen cuándo se configura el apartamiento de la conducta esperada y cuándo corresponde, por tanto, su imposición.

Respecto de la colaboración en materia pericial, del derecho comparado que ha sido relevado se puede extraer que, en menor o mayor medida, todos los sistemas procesales le han fijado, y en algunos casos impuesto, a las partes o a terceros, conductas de ese tenor.

Asimismo, se ha estimado de relevancia la comunicación fluida entre el perito y el juez. El perito debe trasladar al juez todas aquellas cuestiones que puedan afectar la adecuada realización de su dictamen, así como debe plantear, fundamentalmente en los sistemas de designación judicial, todo aquello que entienda oportuno para el cumplimiento efectivo de su encargo.

En ese sentido, se deben canalizada a través del órgano jurisdiccional las solicitudes de exhibición de documentos o la realización de entrevistas o exámenes personales, ya sea a las partes o a terceros. Será el órgano jurisdiccional quien, llegado el momento, tendrá que aplicar las consecuencias procesales negativas ante la ausencia de colaboración, o hacer operativas las medidas de coerción, conminación y/o sanción que se hubiesen previsto, en cada caso, por el ordenamiento.

Se ha destacado también que, si dicha colaboración causare gastos u otro tipo de menoscabo patrimonial a las partes o terceros, resulta lógico que se consigne o pague por los gastos o se los indemnice de algún modo. 


\section{Bibliografía.}

ABAL OLIÚ, A.: Derecho Procesal. Tomo II, quinta edición. FCU, Montevideo, 2016.

ABAL OLIÚ, A.: Derecho Procesal. Tomo IV, primera edición. FCU, Montevideo, 2014.

ABAL OLIÚ, A.: "Cuando debe tenerse por existente un hecho que integra el objeto de la prueba. Valoración de la prueba, presunciones simples y reglas sobre carga de la prueba". En: XVas. Jornadas Nacionales de Derecho Procesal (Mercedes, 2011). FCU, Montevideo, 2011. pp. 19-40.

ABAL OLIÚ, A.: "Admisibilidad, pertinencia, conducencia y necesariedad de los medios probatorios". En: Revista Uruguaya de Derecho Procesal, 3-4/2010. pp. 781-785.

ARLAS, J. A.: "Situaciones jurídicas procesales". En: Revista Uruguaya de Derecho Procesal, 1/1978. pp. 26-35.

BARBOSA MOREIRA, J.C.: "La negativa de la parte a someterse a la pericia médica". En Revista Uruguaya de Derecho Procesal, 1/2003. pp. 13-17.

BÁRCENA ZUBIETA, R. A.: La causalidad en el Derecho de daños. Tesis doctoral. Universitat de Girona, 2012, Portal de Tesis Doctorales en Red (TDR): <http://www.tdx.cat/handle/10803/108448>.

BÁRCENA ZUBIETA, R. A.: "El Derecho de daños como banco de pruebas de una disputa filosófica sobre la causalidad". En: Papayannis, D. M.: Causalidad y atribución de responsabilidad. Marcial Pons, Madrid, 2014. pp. 183-214.

BARREIRO, María Virginia: "Algunas cuestiones prácticas sobre la prueba pericial": En Landoni Sosa, Ángel y Pereira Campos, Santiago: Estudios de Derecho Procesal en homenaje a Eduardo J. Couture, Tomo I. La Ley Uruguay, Montevideo, 2017. pp. 689-708.

BARRIOS DE ÁNGELIS, D.: El proceso civil. Idea, Montevideo, 1989.

BARRIOS DE ÁNGELIS, D.: El proceso civil, segundo volumen. Idea, Montevideo, 1990.

BARRIOS DE ÁNGELIS, D.: Teoría del Proceso, segunda edición actualizada (reimpresión). BdeF, Montevideo, 2005. 
BARRIOS DE ÁNGELIS, D.: "Las situaciones jurídicas y la prueba". En: Revista Uruguaya de Derecho Procesal, 4/2001. pp. 403-408.

BARRIOS DE ÁNGELIS, D.: “Acción, excepción y jurisdicción”. En: Revista Uruguaya de Derecho Procesal, 1/1999. pp. 21-30.

BARRIOS DE ÁNGELIS, D.: "Las situaciones jurídicas". En: Revista Uruguaya de Derecho Procesal, 1/1998. pp. 31-38.

BERRO, G., et al.: Medicina Legal. Derecho Médico y Aspectos Bioéticos. FCU, Montevideo, 2013.

BERRO, G., DÁTTOLE, A., y OLIVERA, H.: "La peritación médicolegal y otros medios probatorios". En: IX Jornadas Nacionales de Derecho Procesal (Rivera-1997). Editorial Universidad, Montevideo, 1997. pp. 195-207.

CAFFERA, G.: Obligaciones. FCU, Montevideo, 2018.

CAFFERATA NORES, J. I.: La prueba en el proceso penal, tercera edición actualizada y ampliada. Depalma, Buenos Aires, 1998.

CARDINAL, F.: "Algunas reflexiones sobre la valoración de la prueba pericial”. En: Revista Uruguaya de Derecho Procesal, 4/1996. pp. 641645.

CARDINAL, F.; KLETT, S.: "El informe del asesor técnico de la parte: su naturaleza jurídica y valoración". En: IX Jornadas Nacionales de Derecho Procesal (Rivera-1997). Editorial Universidad, Montevideo, 1997. pp. 209-217.

CARNELUTTI, F.: Derecho y Proceso, traducción de Sentis Melendo, S. Ediciones Jurídicas Europa - América, Buenos Aires, 1971.

CARNELUTTI, F.: La prueba civil, traducción de Alcalá-Zamora y Castillo, N. Depalma, Buenos Aires, 1982.

CHIOVENDA, J.: Principios de Derecho procesal civil, Tomo II, traducción de la tercera edición italiana. Editorial Reus S.A., Madrid, 1925.

CONDORELLI, E.: "El experto de parte y su legitimación (los consultores técnicos)". En: Morello, A.: La legitimación. Homenaje al Profesor Doctor Lino Enrique Palacio. Abeledo-Perrot, Buenos Aires. pp. 279-294. 1996.

COUTURE, E.J.: El arte del derecho y otras meditaciones. FCU, Montevideo, 2004. 
COUTURE, E.J.: Estudios de Derecho Procesal Civil, tomo II. Depalma, Buenos Aires, 2003.

COUTURE, E.J.: Fundamentos del derecho procesal civil, tercera edición (póstuma). Depalma, Buenos Aires, 1997.

DAMASKA, M.: El derecho probatorio a la deriva, traducción de Picó i Junoy, J. Marcial Pons, Madrid, 2015.

DAMASKA, M.: Las caras de la justicia y el poder del Estado. Análisis comparado del proceso legal. Editorial Jurídica de Chile, Santiago, 2000.

DE MARÍA, P.: Lecciones de Procedimiento Civil, Tomo II. Editor Claudio García, Montevideo, 1920.

DEPARTAMENTO DE MEDICINA LEGAL Y CIENCIAS FORENSES, FACULTAD DE MEDICINA - UNIVERSIDAD DE LA REPÚBLICA: "Pronunciamiento del Departamento de Medicina Legal y Ciencias Forenses sobre la práctica de exámenes corporales periciales sin consentimiento", en $\quad<\mathrm{http} / /$ medicinalegal.edu.uy/wp/wp-content/uploads/2017/06/ Pronunciamiento-del-Departamento-de-Medicina-Legal-y-CienciasForenses 1.pdf $>$ [consultado 04/12/2017].

DEVIS ECHANDÍA, H.: Teoría general de la prueba judicial, Tomos I y II, quinta edición. Víctor P. de Zavalía-Editor, Buenos Aires, 1981.

DEVIS ECHANDÍA, H.: Nociones generales de Derecho procesal civil. Aguilar, 1966.

DÖHRING, E.: La investigación del estado de los hechos en el proceso. La prueba. Su práctica y apreciación. Ediciones jurídicas Europa - América, Buenos Aires, 1972.

DONDI, A.: 'Paradigmi processuali ed 'expert witness testimony' nel diritto statunitense". En: Revista Trimestrale di Diritto e Procedura Civile, Fascicolo I, 1996. pp. 261-285.

ETTLIN, E.: "Sobre la interpretación y valoración de la prueba pericial en el Proceso Civil". En: Revista La Justicia Uruguaya, Año LXXV, Tomo 150,2014 . pp. D-3 a D-24. Sobre la interpretación y valoración de la prueba pericial en el Proceso Civil

Autor: Ettlin, Edgardo

Publicado en: LJU Tomo 150 


\section{Cita Online: UY/DOC/176/2014}

FALCÓN, E.: "La prueba científica". En: Revista del Instituto Colombiano de Derecho Procesal, vol. 38, Instituto Colombiano de Derecho Procesal, 2012. pp. 217-257, <http://www.icdp.org.co/revista/usuarios/ edicionesAnteriores/2012.php>.

FRAMARINO DE MALATESTA, N.: Lógica de las pruebas en materia criminal. Librería Editorial General Lavalle, Buenos Aires, 1945.

GAIERO GUADAGNA, B. J. y SOBA BRACESCO, I. M.: La tutela procesal ante el acoso sexual y moral, segunda edición. La Ley Uruguay, Montevideo, 2016.

GAIERO GUADAGNA, B. J. y SOBA BRACESCO, I. M.: La regulación procesal del habeas data. BdeF, Montevideo, 2010.

GAIERO GUADAGNA, B. J. y SOBA BRACESCO, I. M.: "La sana crítica y la motivación de las decisiones jurisdiccionales en materia probatoria". En: Revista Uruguaya de Derecho Procesal, 3-4/2010. pp. 845-859.

GELSI BIDART, A.: "Significación de la pericia como instituto procesal". En: Revista Judicatura, No 33, 1992.

GOZAINI, O., "La prueba científica no es prueba pericial", en Revista del Instituto Colombiano de Derecho Procesal, vol. 38, 2012, pp. 201-215, Instituto Colombiano de Derecho Procesal: <http://www.icdp.org.co/ revista/usuarios/edicionesAnteriores/2012.php>.

HIGA SILVA, C.A., "La prueba de expertos. Análisis de la racionalidad de este medio probatorio en el derecho", Cuaderno de Trabajo $N^{\circ} 15-$ Departamento Académico de Derecho, Pontificia Universidad Católica del Perú, Lima, 2010.

KLETT, S.: Proceso ordinario en el Código General del Proceso, Tomos I y II. FCU, Montevideo, 2014.

KLETT, S.: "Algunas reflexiones sobre el proceso de valoración de la prueba". En: XXVI Congreso Colombiano de Derecho Procesal, Universidad Libre, Bogotá, 2005. pp. 1023-1062.

KLETT, S.; BALUGA, C.; ÁlVAREZ, F.; CASTILlO, J.: "Principios de la prueba en el sistema procesal civil". En: Revista Uruguaya de Derecho Procesal, 1/2000. pp. 71-107. 
LANDONI SOSA, Á.: "La prueba pericial con especial referencia al proceso civil”. En: IX Jornadas Nacionales de Derecho Procesal (Rivera-1997). Editorial Universidad, Montevideo, 1997.

LANDONI SOSA, Á. (Director); GARDERES, S.; GOMES, F.; GONZÁleZ, M. E. y VAlENTIN, G.: Código General del Proceso de la República Oriental del Uruguay. Comentado, con doctrina y jurisprudencia, Vol. I. BdeF, Montevideo, 2002.

LANDONI SOSA, Á. (Director); GARDERES, S.; GOMES, F.; GONZÁleZ, M. E. y VALENTIN, G.: Código General del Proceso de la República Oriental del Uruguay. Comentado, con doctrina y jurisprudencia, Vol. II-A. BdeF, Montevideo, 2003.

MARABOTTO, J.: "Prueba-Generalidades. Declaración de parte - prueba testimonial". En: AA.VV., Curso sobre el Código General del Proceso, Tomo I. FCU, Montevideo, 1989. pp. 144-145.

MARINONI, L.G. y CRUZ ARENHART, S.: La prueba. Thomson Reuters - La Ley, Santiago de Chile, 2015.

MITIDIERO, D.: Colaboraçao no processo civil. Presupuestos sociais, lógicos e éticos, tercera edición, revisada, actualizada y ampliada. Thomson Reuters, San Pablo, 2015.

MONTERO AROCA, J.: La prueba en el proceso civil, quinta edición. Thomson Civitas, Pamplona, 2007.

NIEVA-FENOLL, J.: "Repensando Daubert: elementos de convicción que debe tener un buen dictamen pericial". En: Picó I Junoy, J. y De Miranda Vázquez, C.: Peritaje y prueba judicial, Bosch Editor, Barcelona, 2017. pp. 85-101.

ORELLANA DE CASTRO, R.: "Un estudio crítico sobre los diferentes sistemas de designación de peritos y sobre las listas de peritos de la LEC". En: Picó I Junoy, J. y De Miranda Vázquez, C.: Peritaje y prueba judicial, Bosch Editor, Barcelona, 2017. pp. 103-157.

PARRA QUIJANO, J.: Manual de derecho probatorio, décimo tercera edición. Ediciones Librería del Profesional, Bogotá, 2002.

PARRA QUIJANO, J.: "Prueba científicas y reglas de valoración". En: XXIV Jornadas Iberoamericanas de Derecho Procesal, Instituto Iberoamericano 
de Derecho Procesal e Instituto Colombo Panameño de Derecho Procesal. Panamá, 2014. pp. 443-454.

PICÓ I JUNOY, J.: "Quince años de prueba pericial: problemas y soluciones” En: Picó I Junoy, J. y De Miranda Vázquez, C.: Peritaje y prueba judicial, Bosch Editor, Barcelona, 2017. pp. 71-83.

PICÓ I JUNOY, J.: El principio de la buena fe procesal, segunda edición. Bosch Editor, España, 2013.

PICÓ I JUNOY, J.: “Conflicto entre garantías constitucionales del proceso. La tensión de los derechos al recurso y a la ejecución en el caso de la ejecución provisional de las sentencias de primera instancia”. En Picó I Junoy: Principios y garantías procesales. Liber Amicorum en homenaje a la Profesora Ma. Victoria Berzosa Francos. Bosch Editor, España, 2013. pp. 41-58.

PICÓ I JUNOY, J.: "La iniciativa probatoria del juez civil: un debate mal planteado". En: Revista Uruguaya de Derecho Procesal, 3/2007. pp. 573590.

PEREIRA CAMPOS, S.: "Moralidad, veracidad y colaboración en el proceso. Incidencia del pensamiento de Eduardo J. Couture en el proceso civil contemporáneo". En: Landoni Sosa, Á. y Pereira Campos, S.: Estudios de Derecho Procesal en homenaje a Eduardo J. Couture, Tomo I, La prueba en el proceso. La Ley Uruguay, Montevideo, 2017. pp. 247-291.

PEREIRA CAMPOS, S.: "Los sistemas de valoración de la prueba". En: Revista Uruguaya de Derecho Procesal, 1/2003. pp. 79-98.

PEREIRA CAMPOS, S.: "El deber de colaboración en la práctica de las medidas probatorias". En: Revista Uruguaya de Derecho Procesal, 4/2000. pp. 511-523.

SALAS CARCELLER, A.: "La prueba pericial civil en la doctrina del Tribunal Supremo". En: Picó I Junoy, J. y De Miranda Vázquez, C.: Peritaje y prueba judicial. Bosch Editor, Barcelona, 2017. pp. 33-46.

SARLO, O., RODRÍGUEZ CARRAU, G., GÓMEZ LEIZA, J., FRANCOLINO, L., DELGADO, S., BURSTIN, D.: La era de los principios: entre compromiso moral y retórica vacía. FCU -Facultad de Derecho de la U de la R, 2018. 
SENTIS MELENDO, S.: La prueba. Ediciones jurídicas Europa-América, Buenos Aires, 1979.

SILVA FORNÉ, D.: La reforma penal. FCU, Montevideo, 2012.

SIMÓN, L.M.: "La prueba entre la oralidad y la escritura". En: Revista Uruguaya de Derecho Procesal, 3/2007. pp. 607-614.

SIMÓN, L.M., y OLIVERA RANGEL, G.: "Los deberes de colaboración y veracidad en el Código General del Proceso". En: Landoni Sosa, Á. y Pereira Campos, S.: Estudios de Derecho Procesal en homenaje a Eduardo J. Couture, Tomo I - La prueba en el proceso. La Ley Uruguay, Montevideo, 2017. pp. 293-314.

SOBA BRACESCO, I. M.: Relación de causalidad y prueba pericial. La Ley Uruguay, Montevideo, 2016.

SOBA BRACESCO, I. M.: "La incursión en el conocimiento científico a través de la prueba pericial. Su impacto en la decisión judicial". En: Revista del Instituto Colombiano de Derecho Procesal, $\mathrm{N}^{\circ}$ 40, 2014. pp. 227-261.

SOZZO, G., BERROS, M.: "Una agenda para el principio precautorio". En: Revista Crítica de Derecho Privado, N 6, Año 2009. pp. 763-793.

TARIGO, E.E.: "Prueba pericial”: en AA.VV.: Curso de Derecho Procesal, Tomo II, segunda edición actualizada. FCU, Montevideo, 1987.

TARIGO, E.E.: Lecciones de Derecho Procesal Civil, Tomo I, octava edición. FCU, Montevideo, 2016.

TARIGO, E.E.: Lecciones de Derecho procesal civil, Tomo II, segunda edición. FCU, Montevideo, 1993.

TARUFFO, M.: La motivación de la sentencia civil. Trotta, Madrid, 2011.

TARUFFO, M.: Simplemente la verdad. El juez y la construcción de los hechos. Marcial Pons, Madrid, 2010.

TARUFFO, M.: La prueba. Marcial Pons, Madrid, 2008.

TARUFFO, M.: El proceso civil adversarial en la experiencia americana. Temis, Bogotá, 2008.

TARUFFO, M.: Sobre las fronteras. Escritos sobre la justicia civil. Temis, Bogotá, 2006.

TARUFFO, M.: La prueba de los hechos. Trotta, Madrid, 2005. 
TARUFFO, M.: "Probabilidad y prueba judicial". En: XXVI Congreso Colombiano de Derecho Procesal, Universidad Libre, Bogotá, 2005. pp. 1077-1091.

TARUFFO, M.: "Conocimiento científico y estándares de prueba judicial" [versión electrónica] En: Boletín Mexicano de Derecho Comparado, nueva serie, año XXXVIII, núm. 114. pp. 1285-1312.

TARUFFO, M., ANDRÉS IBÁÑEZ, P., CANDAU PÉREZ, A.: Consideraciones sobre la prueba judicial, segunda edición. Fundación Coloquio Jurídico Europeo, Madrid, 2010.

VALENTIN, G.: La reforma del Código General del Proceso. FCU, Montevideo, 2014.

VALENTIN, G.: Principio de congruencia y regla iura novit curia, en el proceso civil uruguayo. FCU, Montevideo, 2013.

VALENTIN, G.: "La prueba y la sentencia. Las reglas para determinar la existencia (o inexistencia) de los hechos en el proceso jurisdiccional". En: Revista Latinoamericana de Derecho Procesal, № 2, IJ Editores, 2014, Cita: IJ-LXXV-261, < http://www.ijeditores.com.ar/pop. php?option $=$ publicacion\&idpublicacion $=67 \&$ idedicion $=424>$.

VÁZQUEZ, C.: “¿Cómo mejorar la regulación sobre la(s) prueba(s) pericial(es)? Un marco para incentivar la comprensión judicial de las afirmaciones periciales". En: Picó I Junoy, J. y De Miranda Vázquez, C.: Peritaje y prueba judicial. Bosch Editor, Barcelona, 2017, pp. 277-301.

VÁZQUEZ, C.: De la prueba cientifica a la prueba pericial. Marcial Pons, Madrid, 2015.

VESCOVI, E. (Director); DE HEGEDUS, M.; KLETT, S.; CARDINAL, F.; SIMÓN, L. M.; PEREIRA, S.: Código General del Proceso. Comentado, anotado y concordado, Tomo 4. Ábaco, Buenos Aires, 1998.

VESCOVI, E. (Director); DE HEGEDUS, M.; KLETT, S.; CARDINAL, F.; SIMÓN, L. M.; PEREIRA, S.: Código General del Proceso. Comentado, anotado y concordado, Tomo 5. Ábaco, Buenos Aires, 1998.

ZAGREBELSKY, G.: El derecho dúctil, undécima edición. Trotta, Madrid, 2016. 
